\title{
Research on The Debris Flow Monitoring System Based on Infrasonic Wave
}

\author{
Guan Hongyun \\ College of Information Science and Technology \\ Donghua University \\ Shanghai, China \\ hyguan@dhu.edu.cn
}

\author{
Zhang Hui \\ College of Information Science and Technology \\ Donghua University \\ Shanghai, China \\ 649242230@qq.com
}

\begin{abstract}
Debris-prone areas are widely distributed worldwide, all continents except Antarctic have been harmed by debris flow. Debris flow normally outbreaks all of a sudden, sweeps along fast accompanying with other disasters like landslides, flood and collapse. It has huge destructive power, making severe threats to water conservancy and hydropower, mines, traffic in mountain areas and other engineering facilities as well as local people's lives, property and safety.This task makes an in-depth research on theory of infrasonic wave produced when debris flow occurs. Infrasonic signal collected in the experiment has been transformed with Hilbert-Hang (HHT) which is good at analysis and processing of nonlinear and unstable signals. This system enables to transform debris flow's infrasonic signal collected with infrasonic wave sensor to digital signals by data acquisition card and send it to computer, and then analyze and process such signal using digital signal processing methods in combination of characteristics of infrasonic signal. This research makes an efficient separation of infrasonic signals which are produced by debris flow and environment noises. So in this way, a debris flow monitoring system can be designed based on infrasonic wave.
\end{abstract}

Keywords-debris flow; HHT; infrasonic wave sensor; data acquisition card; monitoring

\section{INTRODUCTION}

Debris flow is a common geological disaster in mountain area. It is formed by rainfalls (including glacier, snow water and rainstorm) diluting mountain with loose soil and sand in valley or gully and steep terrain. It is special torrent entraining large amounts of sediments and rocks and other solid objects during movement. Debris flow normally outbreaks all of a sudden, sweeps along fast accompanying with other disasters like landslides, flood and collapse. It has huge destructive power, making severe threats to water conservancy and hydropower, mines, traffic in mountain areas and other engineering facilities as well as local people's lives, property and safety. In recent years, frequent large scale debris flow disasters in the world have made thousands of people disappeared and being killed, severely harming local people's lives and property.

At present, debris flow is mainly monitored by video or patrol. These traditional monitoring methods hardly guarantee not only the efficiency and accuracy, but also personal safety of monitors on duty in steep terrain. Hence, research and design of a new debris flow monitoring system have great significance for reducing damages caused by debris flow by monitoring it in advance.

Rocks produce infrasonic signal carrying important geological information-infrasonic wave by reason of its fracture, friction and extrusion when debris flow is forming or occurring. Debris flow infrasonic signal is easily diffractive and hardly blocked by obstacles during propagation with low frequency (approximately $0 \sim 20 \mathrm{~Hz}$ ) and long wavelength. The signal decreases very little for difficulty of absorption in air, spreads further afield with very strong penetration force. Sound signal with high frequency may be blocked by a normal thick paper, while debris flow infrasonic signal cannot be blocked even by normal wall.

\section{HHT TRANSFORM}

HHT, a new method for signal processing, is targeting at making signal more suitable to Hibert transform. It is consisted of two parts, one part; also the key part is Empirical Mode Decomposition (EMD) with its core concept of Intrinsic Mode Function (IMF) which could be obtained for Hilbert transform by signal EMD. The other part is Hilbert spectral analysis. The signal would obtain instantaneous amplitude, instantaneous phase and instantaneous frequency and other properties through Hilbert transform and then obtain Hilbert marginal spectrum.

HHT transform accurately reflects signal's timefrequency feature, clearly identifying frequency points with sudden changes at this exact moment, accurately distinguishing dominant frequency without cross-terms and it also has good time-frequency concentration. In previous time-frequency analysis, time resolution and frequency resolution were not compatible due to limits by Heisenberg uncertainty theory which is not a problem for Hibert-Huang transform though. Hilbert spectrum is directly obtained by calculation of IMF components' instantaneous frequencies and instantaneous amplitudes, hence its time resolution and frequency resolution is independent of each other.

\section{DESIGN OF SYSTEM}

Debris flow infrasonic signal is a weak signal with low and unstable frequency, so debris flow monitoring system based on debris flow infrasonic signal identification is striving to collect the weak infrasonic signal that must 
contain a lot of noises and small signal amplitudes. Therefore, signal needs to be processed. It will be transformed with data acquisition card to be digital signal sending to the computer and processed and analyzed by terminal software. The general structure of the system is shown in Fig .1 below:

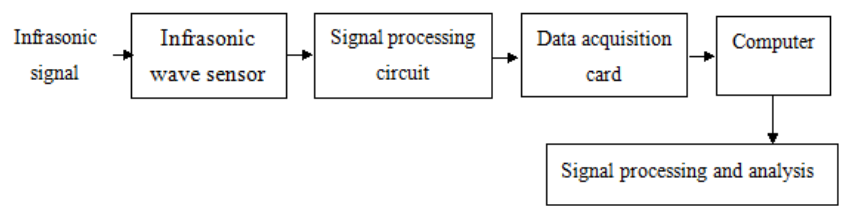

Figure 1. System Structure Diagram

The infrasonic wave sensor which is at front-end of system uses 4189 type sensor(Fig .2) produced in B\&K company, deal with the collected infrasonic signal of debris flow through pre-amplification and filtering process, enter into the computer after experiencing $\mathrm{AD}$ transition and sampling through a data acquisition card NI9234 which shown in Fig .3. Finally, the computer will finish the process of infrasonic signal of debris flow, waveform display and feature analysis. Please refer to the Fig .4 for the complete experimental device.

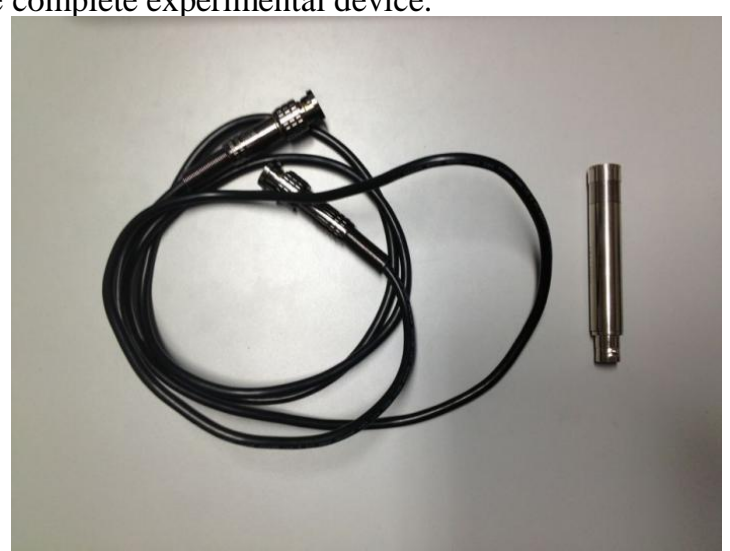

Figure 2. B\&K4189 Infrasonic Wave Sensor

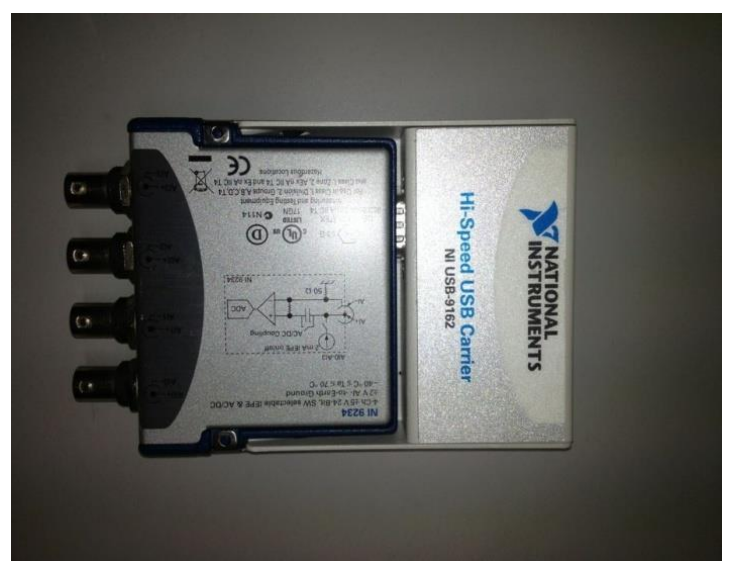

Figure 3. NI9234 Data Acquisition Card

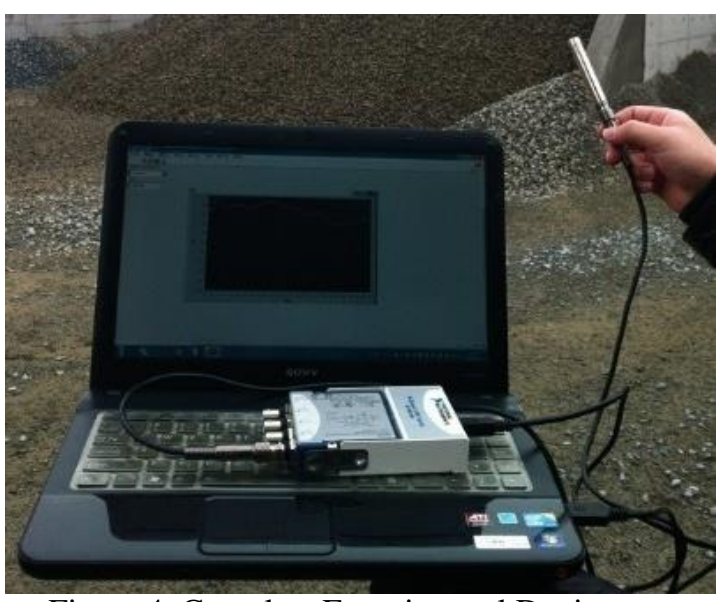

Figure 4. Complete Experimental Device

\section{COLLECTION AND ANALYSIS OF DEBRIS FLOW INFRASONIC SIGNAL}

\section{A. Collection of Debris Flow Infrasonic Signal}

Debris flow is sporadic and hazardous, thus it is very difficult to directly collect debris flow infrasonic signal. Hence, after analysis and research on such signal, experiment imitating it was designed to collect infrasonic signal similar to that produced when debris flow disaster occured. After research on the relevant documents, it has been found that location where concrete mixer runs or conveyor runs for dumping sand were also able to produce infrasonic signal similar to debris flow infrasonic signal. In view of this, a construction site where had running concrete mixer has been chosen to collect infrasonic signal.

Laboratory collected two kinds of infrasonic signals including one for background noise only and one for both background noise and infrasonic signal with same instrument set. Signal samples were collected once every second for two minutes with frequency of $22.5 \mathrm{KHz}$. the experimental data is recorded as below:

\section{1) Background Noise}

Background noise was audio signal collected when concrete mixer was not running, as shown in Fig .5(a), the signal was collected when concrete mixer was not running. Frequency spectrogram for such signal is shown as Fig .5 (b): 


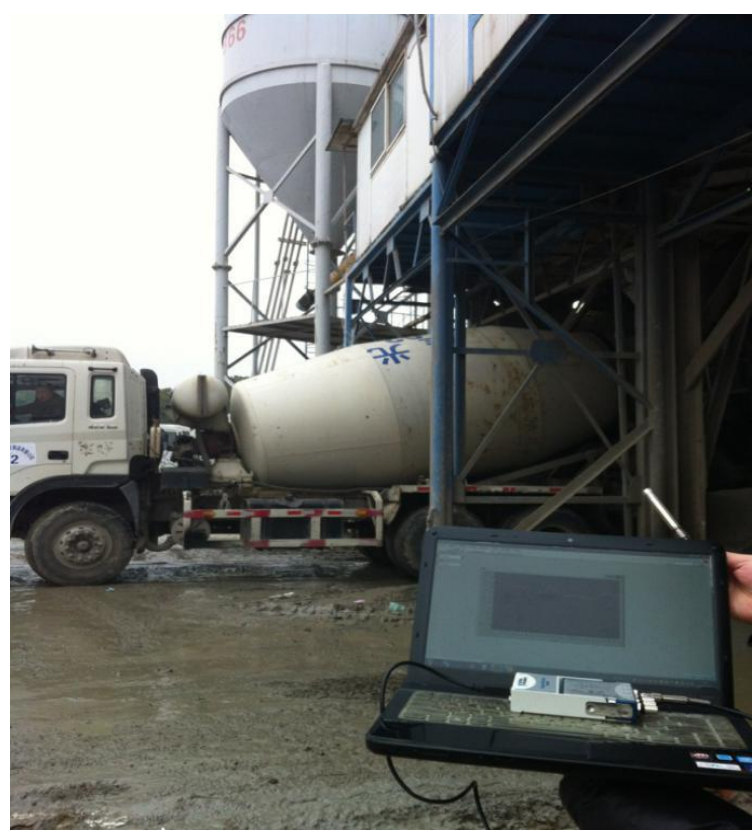

Figure 5(a). Collecting Background Noise

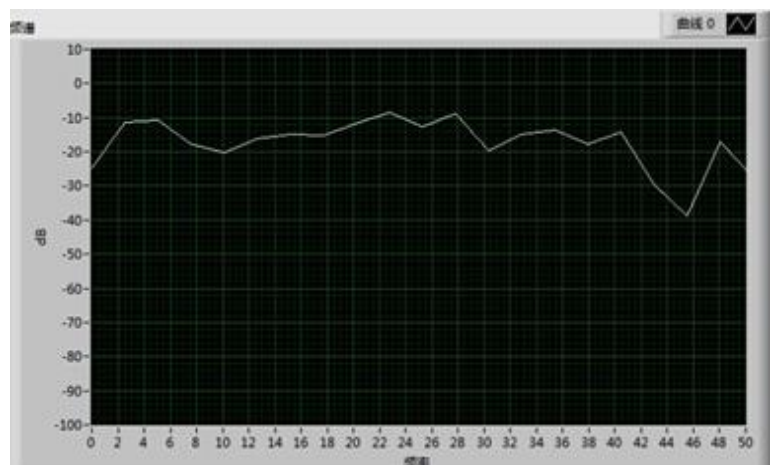

Figure 5(b). Frequency Spectrogram of Background Noise

The $\mathrm{X}$ axis of figure 5(b) is frequency which unit is $\mathrm{Hz}$, and the $\mathrm{Y}$ axis is power which unit is $\mathrm{dB}$. We can see from the Frequency Spectrogram that the power of the frequency which is below $20 \mathrm{~Hz}$ is around between $-20 \mathrm{~dB}$ and $-10 \mathrm{~dB}$.

2) Audio Signals Collected When Concrete Mixer is Running

Don't change the settings of experimental apparatus and collect audio signals when concrete mixer is running normally, as shown in Fig .6(a). Frequency spectrogram for such signal is shown as Fig .6 (b):

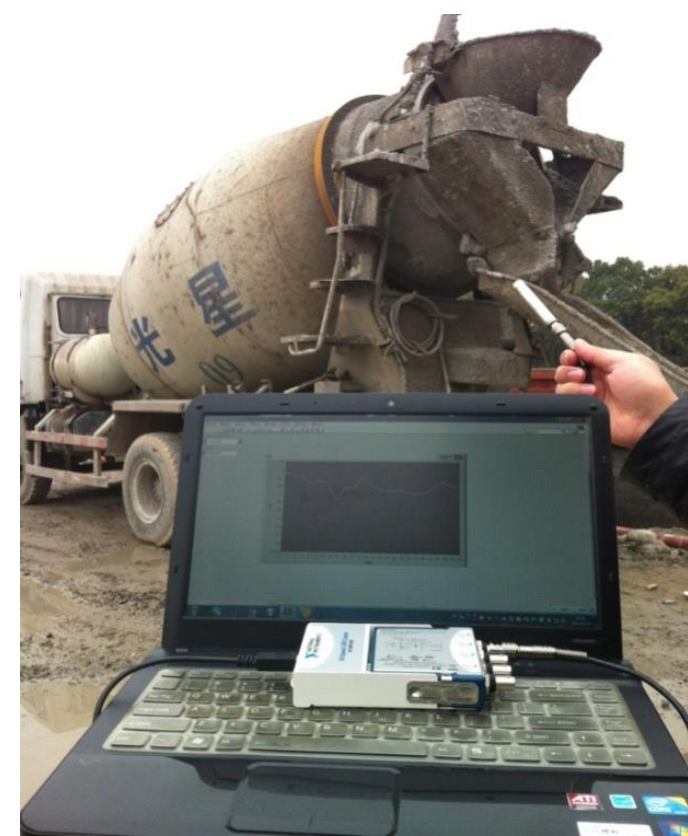

Figure 6(a). Audio Signals Collected When Concrete Mixer is Running

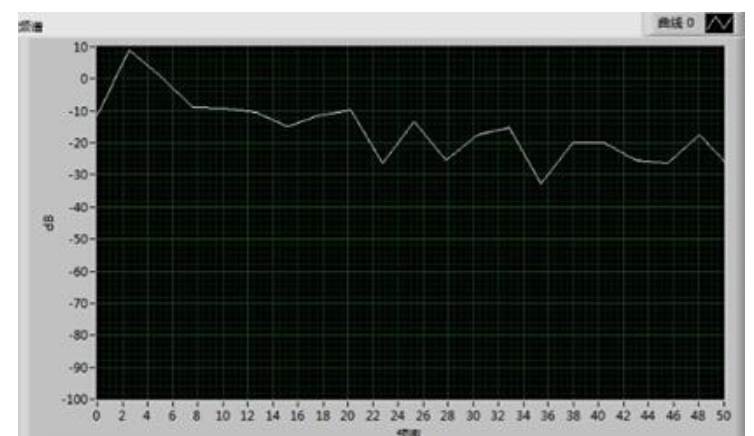

Figure 6(b). Frequency Spectrogram of Audio Signals Collected When Concrete Mixer is Running

We can see from the figure 6(b) that the power of the frequency which is below $20 \mathrm{~Hz}$ has changed when concrete mixer is running, especially when frequency below $16 \mathrm{~Hz}$, its power changed a lot. However, the power of the frequency which is above $20 \mathrm{~Hz}$ has almost unchanged. The reason is that there are all kinds of noises when collecting audio signals, such as the movement of vehicles and people, so the power of the frequency which is above $20 \mathrm{~Hz}$ has always maintained a certain state and not changed obviously.

\section{B. Date Analysis}

In the process of signal acquisition, we can find that the signals collected when concrete mixer is running or not are quite differernt. When concrete mixer is not running, the power of the infrasonic wave which frequency is below $20 \mathrm{~Hz}$ is between $-20 \mathrm{~dB}$ and $-10 \mathrm{~dB}$. The power of the frequency which is above $20 \mathrm{~Hz}$ is generally about $-20 \mathrm{~dB}$. When concrete mixer is running, the power of the infrasonic wave is above $-10 \mathrm{~dB}$, especially between $2 \mathrm{~Hz}$ and $8 \mathrm{~Hz}$, the power even up to $10 \mathrm{~dB}$. But at this time, The power of the frequency which is above $20 \mathrm{~Hz}$ is still about $-20 \mathrm{~dB}$. Therefore, through the experiments we can draw a 
conclusion that as for infrasonic frequency, the power of the debris flow signal increased obviously than the power of the background noise, so that we can separate debris flow signal from background noise.

\section{CONCLUSION}

Debris flow is a common disastrous question face to the people all over the world. This task makes analysis and research on formation theory and characteristics of infrasonic wave during outbreak of debris flow and makes the following conclusion:

1) Existence of infrasonic signal when debris flow occurs

Changes to audio signal within infrasonic wave range when concrete mixer is running are bigger than those to background noise and lots of environment noises within audibility zone exist, hence infrasonic frequency is the only thing to analyze.

2) Separability of Infrasonic Signal and Environment Noise

Energy changes of infrasonic signal and those of noninfrasonic signal are different no matter the concrete mixer is running or not. Infrasonic signal changes a lot while signal within audibility zone and signal with high frequency basically remain unchanged. This conclusion can be used for separation of infrasonic signal and environment noise.

This task, taking energy changes of infrasonic wave produced in process of forming debris flow as basis of predicting whether debris flow occurs. So in this way, we can design debris flow monitoring system based on infrasonic wave to monitor debris flow disaster in real time.

\section{REFERENCES}

[1] Liu Xi-lin, "Study on assessment of debris flow hazard ," Journal of Catastrophology,vol. 3,pp. 10-15, September 2009(In Chinese).
[2] Shu Fang, Jing-xue Jiang, Zhen-wei Zhang, The Analasis of Combustion Audio Signals based on Continuous Wavelets Transform, Symposium on Piezoelectricity, Acoustic waves, and Device Application(2011),p.282-285.

[3] the Chinese Academy of Sciences and Ministry of water conservancy Chengdu Institute of mountain hazards and environment, the second national conference of debris flow, Science Press,2001,298-300.

[4] Tang Chuan, Zhu Jing, Study on landslide and debris flow in Yunnan, The Commercial Press, 2003,47-75.

[5] Zhang Shucheng, Jingri Chen, Ye Mingfu. Test and research of Jiangjiagou debris flow physical parameters, "Observation and research of Yunnan Jiangjiagou debris flow" [M]. Beijing science and Technology Press, 1990:156-164.

[6] J. R. McGrath, "Infrasonic sea noise measurements and experimental problems," Acustica, vol. 38, pp. 324-327, 2007.

[7] Xiaoan Qin. Traveling Waves Protection Methods Using Hilberthuang Transform Transform for Transmission Lines. Changsha Science and Techonlogy University. 2010

[8] Chang Yong,Zhang Ping,Wang Yu-sheng. HVDC traveling wave protection based on Hilbert-Huang transform. Electric Power. 2011, vol 11, 14-18.

[9] L. Qian, G. Xu, W.Tian, and J.Wang, A novel hybrid EMD-based drift denoising method for a dynamically turned gyroscope (DTG), Measurement, 42(6) 2009,927-932.

[10] I. Simon Haykin, David J. Thomson and Jeffrey H. Reed "Spectrum Sensing for Cognitive Radio", Proceedings of the IEEE, Vol. 97, No.5, May 2009

[11] Mansi Subhedar and Gajanan Birajdar, "Spectrum Sensing Techniques In Cognitive Radio Networks: A Survey", International Journal of Next-Generation Networks (IJNGN) Vo1.3, No.2, June 2011

[12] Ge Zhexue, Chen Zhongsheng, "MATLAB time-frequency analysis technology and its application" [M], the posts and Telecommunications Press. Beijing: Chen Sheng, 2006.

[13] J. C. Bregains, J. A. Garcia-Naya, M. Gonzalez-Lopez, and L. Castedo-Ribas, "A MATLAB Interface for Analyzing Conformal Arrays Composed of Polarized Heterogeneous Elements," IEEE Antennas and Propagation Magazine, 53, 5, October, 2011, pp. 136-144. 